\title{
Haematological profile of hospitalised COVID-19 patients from a centre in Singapore
}

\author{
Valencia Long ${ }^{1}$, Jinghao Nicholas Ngiam${ }^{1}$, Nicholas WS Chew ${ }^{2}$, Sai Meng Tham ${ }^{1}$, Zhen Yu \\ $\mathrm{Lim}^{1}$, Tony $\mathrm{Li}^{1}$, Shuyun $\mathrm{Cen}^{2}$, Jayagowtham K Annadurai ${ }^{3}$, Sandi Myo Thant ${ }^{3}$, Paul \\ Anantharajah Tambyah ${ }^{1}$, Amelia Santosa ${ }^{1}$, Winnie Ziyun Teo ${ }^{4}$, Eng Soo Yap ${ }^{4}$, Gail \\ Brenda Cross ${ }^{1}$, and Ching Hui Sia ${ }^{1}$ \\ ${ }^{1}$ National University Health System \\ ${ }^{2}$ National University Heart Centre \\ ${ }^{3}$ NUS Yong Loo Lin School of Medicine \\ ${ }^{4}$ National University Cancer Institute
}

February 24, 2021

\begin{abstract}
Background: Haematological markers such as absolute lymphopenia has been associated with severe COVID-19 infection. However, the described cohorts were generally unwell with a large proportion of patients requiring intensive care stay. It is uncertain if these markers apply to a population with less severe illness. We sought to describe the haematological profile of patients with mild disease with COVID-19 that were admitted to a single centre in Singapore. Methods: We examined 554 consecutive PCR positive SARS-COV-2 patients who were admitted to a single tertiary healthcare institution from Feb 2020 to April 2020 2020. We examined patients based on their haematological profile based on full blood count obtained within 24h of presentation. Results: Patients with pneumonia had higher neutrophil percentages (66.5 \pm 11.6 vs $55.2 \pm 12.6 \%, \mathrm{p}<0.001)$, lower absolute lymphocyte count $(1.5 \pm 1.1$ vs $1.9 \pm 2.1 \times 109 / \mathrm{L}, \mathrm{p}<0.011)$ and absolute eosinophil count $(0.2 \pm 0.9$ vs $0.7 \pm 1.8$ $\mathrm{x} 109 / \mathrm{L}, \mathrm{p}=0.002)$. Platelet counts $(210 \pm 56$ vs $230 \pm 61, \mathrm{p}=0.020)$ were slightly lower in the group with pneumonia. We did not demonstrate significant differences in the neutrophil-lymphocyte ratio, lymphocyte-monocyte ratio and platelet-lymphocyte ratio in patients with or without pneumonia. Sixty-eight patients $(12.3 \%)$ had peripheral eosinophilia. This was more common in migrant workers living in dormitories. Conclusion: Neutrophilia and lymphopenia were found to be markers associated with severe COVID-19 illness. We did not find that combined haematological parameters: NLR, MLR and PLR, had any association with disease severity in our cohort of patients with mild-moderate disease. Migrant workers living in dormitories had eosinophilia which may reflect concurrent chronic parasitic infection.
\end{abstract}

\section{Hosted file}

COVID haematology v14 final untracked format.pdf available at https://authorea.com/users/ 397801/articles/510593-haematological-profile-of-hospitalised-covid-19-patients-from-acentre-in-singapore

\section{Hosted file}

COVID_Haematology_tables for submission v1.pdf available at https://authorea.com/users/ 397801/articles/510593-haematological-profile-of-hospitalised-covid-19-patients-from-acentre-in-singapore 